\title{
Pandemic preparedness strategies for school systems: is closure really the only way?
}

\author{
Eric T. Lofgren ${ }^{1}$, Jeremiah Rogers ${ }^{2}$, Margaret Senese ${ }^{2,3}$ \& \\ Nina H. Fefferman²,*
}

1) Department of Epidemiology, School of Public Health, University of North Carolina at Chapel Hill, 2106 McGavran-Greenberg, CB \#7435, University of North Carolina, Chapel Hill, NC, 27599, USA

2) DIMACS Center, CoRE Building, 4th Floor, Rutgers University, 96 Frelinghuysen Road, Piscataway, NJ, 08854, USA (corresponding author's e-mail: feferman@math.princeton.edu)

3) Tufts University Summer Scholars Program, Tufts Summer Scholars, Tufts University, Dowling Hall, Suite 710, 419 Boston Avenue, Medford, MA 02155, USA

Received 2 Sep. 2007, revised version received 15 June 2008, accepted 16 June 2008

Lofgren, E. T., Rogers, J., Senese, M. \& Fefferman, N. H. 2008: Pandemic preparedness strategies for school systems: is closure really the only way? - Ann. Zool. Fennici 45: 449-458.

School closure at the outset of epidemic outbreaks has been recommended as one of the best ways to protect children and prevent amplifying the outbreak by gathering susceptible individuals, with relatively poor hygiene, into close contact, and then sending them back out to mix with society at large. However, school closure is not without its own, potentially critical, impact on the function of society. Outbreak-related workforce depletion is already another major concern of pandemic preparedness planners, and caring for children during the day may drastically contribute to adult absenteeism from work. We present a series of computational models to examine whether alternative inschool strategies could provide some measure of infection control without producing the same societal burden in finding alternative childcare. These investigations lead to the conclusion that some non-closure options may provide the best societal protection, finding an appropriate balance between preventing further infection and compromising general societal function.

\section{Introduction}

A great deal of attention has recently been given to the potential for an infectious disease pandemic to wreak havoc on a global scale. Both the popular press and the scientific literature have presented articles studying the probabilities of such an event, the health and economic impact, which pathogenic agents might be more likely to pose such a risk, and, of course, whether specific interventions may help curtail the damage. As a result of this research and popular attention, organizations ranging in complexity and scope from small businesses and single families, to state and federal governments, and even international health organizations have begun to look into this issue. The resulting "preparedness plans" to combat the spread of these hypothetical pandemic diseases have incorporated many potential interventions meant to arrest the secondary transmission of infection. One of the most commonly discussed is the closure of schools (cf. Bro- 
ward County Public Schools Pandemic Action Plan 2006, Pandemic Preparedness - New York Department of Education 2006, Secretary Spellings Address to the North Carolina Pandemic Planning Summit 2006, Community Strategy for Pandemic Influenza Mitigation - PandemicFlu. gov 2007).

The impact of infectious diseases in children still remains a problem, in both the developed and developing worlds, even under normal, currently existing disease levels (cf. Bhat et al. 2003 and Black et al. 2003, respectively). Children experience heightened susceptibility to a wide range of potential pathogens, and often suffer from much less favorable outcomes than healthy adults (e.g. influenza; cf. Bocchini et al. 2008). Schools and other childcare facilities represent an epidemiologically important source of infection in the broader community since they gather children together, involving very high contact rates, relatively confined spaces, and countless opportunities for disease transmission through direct contact or interaction with contaminated material (cf. Dyer et al. 2000).

Epidemiological models projecting the course of such a pandemic suggest that closing schools may, for reasons outlined above, be warranted. Not only is such a strategy expected to protect the health of the children directly from the heightened levels of contact, and therefore disease circulation, but would eliminate the schools from serving as disease reservoirs, causing epidemic amplification (e.g. Ridzon et al. 1997, Villar et al. 1998, Hammond et al. 2000). This prediction yields hope that school closure would provide further protection to society as a whole.

While these benefits would no doubt greatly aid in combating the outbreak, those concerned with designing strategies to prepare for such a grave happening are also concerned with preventing the breakdown of critical infrastructure and services. Essential services such as medical, fire, and police protection (Community Strategy for Pandemic Influenza Mitigation - PandemicFlu.gov 2007) have all instituted plans to cope with the expected disease-related workforce depletion. Thus far, the focus has largely been on either directly disease-related absence, or else on voluntary absenteeism of workers in critical positions due to fear of infection (cf. Pandemic
Influenza Preparedness and Response Guidance for Healthcare Workers and Healthcare Employers - OSHA 3328-05 2007). School closures may indirectly create another major source of mass absenteeism; any school closure would require either at least one parent to stay home or, alternatively, would force the family to find alternate providers of childcare outside school. Daycare centers themselves would simply be gathering children at an alternate location, negating the intended effects of school closure in the first place (Community Strategy for Pandemic Influenza Mitigation - PandemicFlu.gov 2007). This effect could contribute significantly to a breakdown of societal infrastructure at a critical moment. Further, over and above the issue of a pandemic, these kinds of school policies can have large economic, social, and health ramifications, and warrant critical examination before any such strategy should be implemented.

Here we examine a number of potential alternative strategies to school closure in the face of an infectious disease using an agent-based computational model. We created a simplified elementary school layout to test a variety of intervention policies against a baseline model in which no intervention was attempted. To capture transmission among students, infection was defined to result both from direct contact with infectious children, and also to be possible as the result of contacting infectious material shed into the environment by the earlier presence of infected children. The shed infectious agents were assumed to dissipate, die, or in some other way become inactive over time. To the best of our knowledge, this is one of the first models to incorporate local environmental contamination of dissipative infectious particles by the movement of individuals, rather than relying solely on direct contact among infectious individuals, or else on an external flow (of air or water), to carry infectious contamination along its path.

Our infectious disease was defined to provide no protective immunity, allowing for re-infection after recovery. While this does not reflect the etiology of diseases of greatest concern for pandemic preparedness, it does make it significantly harder for any intervention to succeed at controlling a spreading infection. As a result, these comparisons of efficacy are more conservative, 
examining the ability to control the most difficult spread dynamics. Further work will, of course, be needed to examine the potential of specific control probabilities to protect the community against any one particular disease of concern and the associated etiology of its spread.

The alternative strategies presented focus primarily on opportunities to cut transmission rates, and thus the opportunity for children to spread the disease to their classmates, while keeping them in school. We examined the success of the popularly recommended school closure policies and compared them with the efficacy of altering the sensitivity threshold of already existing policies that send children home when they begin to show symptoms of disease in response to earlier disease incidence. Further, since many primary schools utilize single-classroom educational models, bringing the students together into larger groups during lunch, recess and school assemblies, we investigated the effects of restricting cross-classroom interactions. As an extreme baseline from which to examine alternatives, we also examined a "no walls" school. While not strictly representative of school designs, this model can be interpreted in two ways, both of critical interest: as representing a secondary school structure, in which students routinely switch classrooms and re-assort among their peers throughout the day, and as larger day care centers. Such alternatives, if successful, could curtail the effect of epidemic amplification, while avoiding any of the possible cascading indirect effects to both the workforce and to individual families. These models provide initial estimates for the efficacy of alternative school-related pandemic preparedness plans which will hopefully inform future studies into the relative costs and benefits to society as a whole, under outbreak scenarios, for particular intervention strategies.

\section{Methods}

\section{Standard model}

The model's school layout consisted of 10 classrooms, each an $8 \times 8$ grid housing 20 students, and a larger common area of size $20 \times 20$, representing a cafeteria and social area. Each student occupied one cell of the grid, and was capable of interacting with the immediate "neighborhood" of adjacent cells (limited by the perimeter of the space). Students were assumed to be in their classrooms from 9 am to 11 am and from 1 pm to 3 pm during a normal week. Movement during these periods was determined by each student independently moving toward a randomly chosen target in the room at a rate of one cell per time unit. From $11 \mathrm{am}$ to $1 \mathrm{pm}$ the students were together in the common area and moved three times faster, representing the more rapid and chaotic movement of students who were no longer expected to remain predominantly seated at a desk. During the weekends and all hours after 3 pm until 9 am the next day, the students were "at home" and isolated from contact with other students.

At each time step, an infected student would shed 100 infective particles (representing a disease with a moderate minimum infective dose; cf. Conly \& Johnston 2003, Suarez 2005) into the cell they occupied, and 50 infective particles into their immediately adjacent neighborhood. The level of infectious material per cell was capped at a maximum of 100 units, representing the point when other biological factors, rather than infectious dose, begin to determine whether or not a student is infected. The infectious material decayed at a rate 10 particles per time step.

The disease process itself was determined according to a hypothetical infection relationship between exposure and infection: the probability of infection for each student occupying a grid cell at the center of their own neighborhood $=$ $0.11\left(1-0.7^{X}\right)$, where

$$
X=0.3\left(\sum_{\text {neighborhood }} a\right)+0.005\left(\sum_{\text {neighborhood }} b\right)
$$

and $a=\{1$ if an infected child occupies the grid space and 0 otherwise $\}$, and $b=$ the amount of infectious material in the grid space. (Note: these equations were chosen solely to provide a reasonable first approximation of a disease process; more accurate, empirically supported relationships would be of great benefit to the realism of model outcomes.)

The course of each student's disease began with an asymptomatic period (mean duration = 48 hours, $\mathrm{SD}=6$ hours) during which the student was contagious through direct contact but did not 
shed infectious material into his or her surroundings (i.e. the student contributed to $a$, but not to $b$ ). Following this period, the student entered a symptomatic, infectious period (mean duration $=48$ hours, $\mathrm{SD}=12$ hours) during which material was shed into surroundings and schools were considered able to identify infected (and therefore infectious) students.

Student health was represented by a unit-less health counter from 0 to 100 , initially set to 100 for all students and decreased by 5 every hour (one hour $=$ five time steps) during the symptomatic period when at school. Students sent home from school had their health score remain unchanged for a period of 3 hours, after which they were assumed to recover at the rate of 2 health units per hour. (Again, these rates were chosen to represent a generic disease, but could be tailored appropriately for different specific diseases, and could be extended to include the effects of active treatment.)

In each of the modeled scenarios, the schools used a student's health score to determine at what point the students should be sent home. In the baseline model, the school's threshold was defined to be 60 . Additionally, each student had their own threshold preference at which they would ask to be sent home. This was defined to have a mean 60 with $\mathrm{SD}=5$, (though a student with a threshold lower than 60 would be sent home by the school before asking to leave). Lastly, each student was defined to have some health threshold of recovery, past which they would return to school after being home sick $($ mean $=70, \mathrm{SD}=5)$. This recovery was independent of actual recovery from the disease, meaning that students who felt better, but were still infectious would return to school, possibly to feel worse again and then again go home.

\section{Experimental scenarios}

To examine the effects of school policies, modifications were made to the baseline model exploring the relationship between school structure and the progression of the in-school outbreak (Table 1). By comparing the baseline outcomes with those from the modified scenarios, we explored the effect of having a well defined classroom struc- ture versus a single large common area (meant to represent the 'change classroom with topic' student flow model common to high schools), varying the length of mandatory absence for symptomatic children, closing the common area at certain levels of illness, closing the school entirely, or governing school policy for when to send children home sick based on a variable threshold (instead of the constant threshold of 60 in the baseline scenario) of sensitivity, defined as: Health at which the school will send a sick child home $=60+s(\%$ Sick $)$, where the value of $s$ was set between 0.5 and 3.0, and \%Sick was the percentage of students already out sick at that time. Generally, this policy increases the likelihood of beginning to send students home with less severe or fewer symptoms as more students become clearly ill, dynamically bridging the gap between mandatory absence and school closure models (the maximum value of the threshold being 100, equivalent to closing the school).

Each model was run for 7000 time steps, or roughly 58 days, with the first eight days (1000 time steps) removed from the analysis of the outcome data. (Note: While examining the relative dynamics of the early stage of an outbreak may itself prove worthwhile, we were more concerned about control once a disease had already exposed some non-zero portion of the school's population, as we would expect during an outbreak, hence our examination conservatively focused only after a week long spread period had already occurred. Further studies may yield important results about purely preventative control measures in the absence of established infection.) The simulation began on a Monday, representing again a most conservative, worst-case scenario with the maximal potential for infections before the break in contact that accompanies the weekend. Our observations confirm that endemic levels of disease stabilized into a weekly pattern after this initial eight-day period (data not shown). We computed 300 realizations of each scenario; all statistical analysis was performed using JMP 7 (SAS Institute, Cary, NC).

\section{Results}

For the purposes of this analysis, we present 
those model outputs describing (interrelated) outcomes of the disease dynamics within the school which are most relevant to informing policymakers and school administrators (Table 2). Additionally, as they examine different aspects of policy, the results of the "School Structure" and "School Policy" models are presented separately. It should be noted that model realizations of any scenario in which the total unique number of infections was 0 (indicating a failure of the disease to establish itself initially) were omitted from the statistical comparison of the modeled scenarios since they could not have shed light on the impact of the control strategy.

\section{School structure models}

The school structure models showed consistent and largely statistically significant results across all four of our measured outcomes. In each, the "unstructured" school, lacking classrooms but having a large common area, had considerably worse outcomes across the board. The unstructured school showed a significantly lower average student health score (mean student health of $94.6 \mathrm{vs}$. 95.4 in the structured school, $t=$ $-46.03, p<0.005)$. Students in the unstructured school were additionally more likely to be sent home from school (mean number of students

Table 1. Modeled scenarios.

\begin{tabular}{|c|c|c|c|}
\hline & Name & Description & Scenario code \\
\hline \multirow[t]{2}{*}{$\begin{array}{l}\text { School structures } \\
\text { intervention (Fig. 1) }\end{array}$} & $\begin{array}{l}\text { Classroom } \\
\text { structure }\end{array}$ & $\begin{array}{l}\text { Students were segregated during class time } \\
\text { into } 10 \text { separate classrooms, mixing together in } \\
\text { a single common area only at lunch and free time. }\end{array}$ & \\
\hline & No classrooms & $\begin{array}{l}\text { All students were in the large common area all day, } \\
\text { students still moved three times faster from } 11 \text { am } \\
\text { to } 1 \mathrm{pm} \text {. }\end{array}$ & \\
\hline \multirow[t]{5}{*}{$\begin{array}{l}\text { School policy } \\
\text { intervention (Fig. 2) }\end{array}$} & Baseline model & $\begin{array}{l}\text { Standard model, symptomatic students } \\
\text { are required to leave school but may return } \\
\text { as soon as their health exceeds the school's } \\
\text { leaving threshold. }\end{array}$ & $B L$ \\
\hline & $\begin{array}{l}\text { Mandatory } \\
\text { absence }\end{array}$ & $\begin{array}{l}\text { Symptomatic students are required } \\
\text { to leave school for } 1,3,5 \text { or } 10 \text { days. }\end{array}$ & $\begin{array}{l}\text { MA01, MA03, } \\
\text { MAO5, MA10 }\end{array}$ \\
\hline & $\begin{array}{l}\text { Playground } \\
\text { closing }\end{array}$ & $\begin{array}{l}\text { Playground/common area closed when } 5 \% \text {, } \\
10 \%, 20 \% \text { or } 30 \% \text { of students are ill. }\end{array}$ & $\begin{array}{l}\text { PC05, PC10, } \\
\text { PC20, PC30 }\end{array}$ \\
\hline & School closing & $\begin{array}{l}\text { School closes entirely when } 2 \%, 10 \% \text { or } \\
35 \% \text { of students are ill }\end{array}$ & $\begin{array}{l}\text { SC02, SC10, } \\
\text { SC35 }\end{array}$ \\
\hline & $\begin{array}{l}\text { Threshold } \\
\text { absences }\end{array}$ & $\begin{array}{l}\text { The threshold at which students are sent } \\
\text { home is more sensitive as more students } \\
\text { become ill. Coefficient values for determining } \\
\text { the threshold were set at } 0.5,1.0,2.0 \text { and } 3.0 \text {. }\end{array}$ & $\begin{array}{l}\text { VT0.5, VT1.0, } \\
\text { VT2.0, VT3.0 }\end{array}$ \\
\hline
\end{tabular}

Table 2. Outcomes examined.

\begin{tabular}{|c|c|c|}
\hline Name & Description & Indication of efficacy \\
\hline Total unique infected & $\begin{array}{l}\text { The maximum number of unique infected } \\
\text { students at any one time }\end{array}$ & $\begin{array}{l}\text { Low number of infected } \\
\text { students }\end{array}$ \\
\hline Total sick days & $\begin{array}{l}\text { Total number of sick days experienced by } \\
\text { the student population }\end{array}$ & $\begin{array}{l}\text { Low number of missed } \\
\text { school days }\end{array}$ \\
\hline Mean sent home & $\begin{array}{l}\text { Mean number of students who had been } \\
\text { sent home at any one time }\end{array}$ & $\begin{array}{l}\text { Low number of students sent } \\
\text { home }\end{array}$ \\
\hline Average health & $\begin{array}{l}\text { The average health score of students during } \\
\text { the simulation }\end{array}$ & $\begin{array}{l}\text { High health scores ( } 100 \text { is the } \\
\text { maximum) }\end{array}$ \\
\hline
\end{tabular}



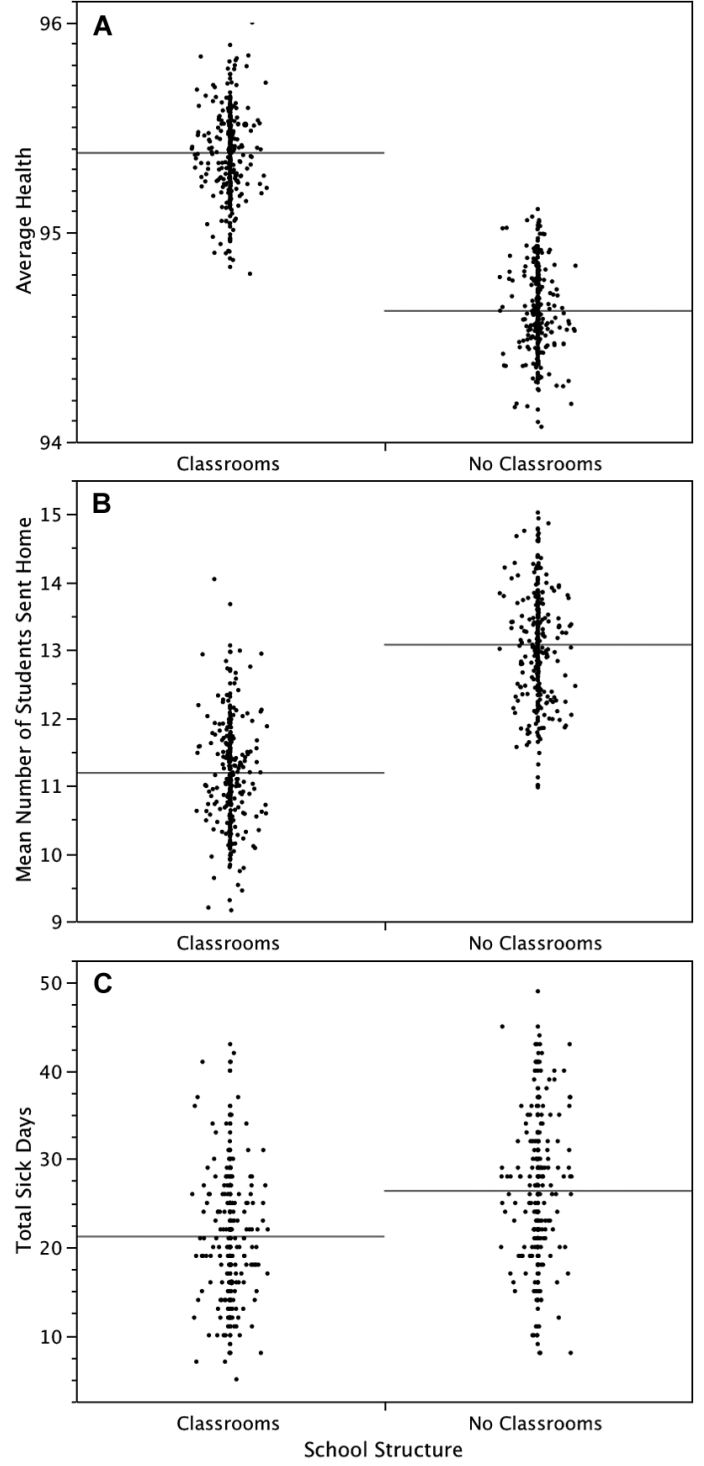

Fig. 1. Effect of school structure on model outcomes. Comparing a school with classroom structure to a school with only a single, large common area. Outcomes of interest were the average health score for $(\mathbf{A})$ students out of $100,(\mathbf{B})$ the mean number of students who had been sent home at any given time point, and $(\mathbf{C})$ the total number of sick days experienced by the students. For all three outcomes, the unstructured model had consistently less favorable outcomes. (Data points jittered to clarify distribution of data; single solid line represents the mean value.)

sent home of $13.1 \mathrm{vs} .11 .2, t=30.15, p<0.005)$, and missed a greater number of total days of school $($ mean $=26.4$ total sick days $v s .21 .2, t=$
$8.38, p<0.005)$ (Fig. 1). Only the total number of students ever infected failed to produce a statistically significant difference in the result: both models produced a mean of 200 infected students with no variance, indicating that for all realizations of the model, both structures utterly failed to actually prevent an epidemic from spreading to all students.

\section{School policy models}

The school policy models also showed marked variation in model outcomes (summarized in Fig. 2). For average health scores, there were significant differences achieved by the possible intervention strategies. Scenarios modeling playground closing, short-duration mandatory absences, and low variable threshold coefficient values typically performed poorly for this metric. Not surprisingly, zero-day mandatory absence performed least well, with an average student health of 95.36. Scenarios modeling school closure, or high variable threshold coefficient values, as well as the ten-day mandatory absence model, performed more favorably, with a school closure at $2 \%$ achieving the highest average student health, of 99.78 (one-way ANOVA: $F=$ $9151, p<0.005$, post-hoc testing with Tukey's HSD, $\alpha=0.05)$.

Significant differences were also found between model outcomes for the mean number of students sent home. The school closure models universally had lower numbers of students sent home (Note: this only reflects students sent home from an open school due directly to illness), with a closure at $2 \%$ of students ill having an average of only 1.17 students sent home and a closure at $35 \%$ of students ill having an average of 7.57 students sent home. Playground closing models followed this, with a range of 9.02 to 10.96 students sent home. Variable threshold and mandatory absence models had the largest numbers of students sent home, with the ten day mandatory absence scenario having the highest average at 63.03 students (one-way ANOVA: $F=22511.13$, $p<0.005$, post-hoc testing with Tukey's HSD, $\alpha$ $=0.05$ ).

As discussed previously, the total unique infected outcome functions as a measure of a 

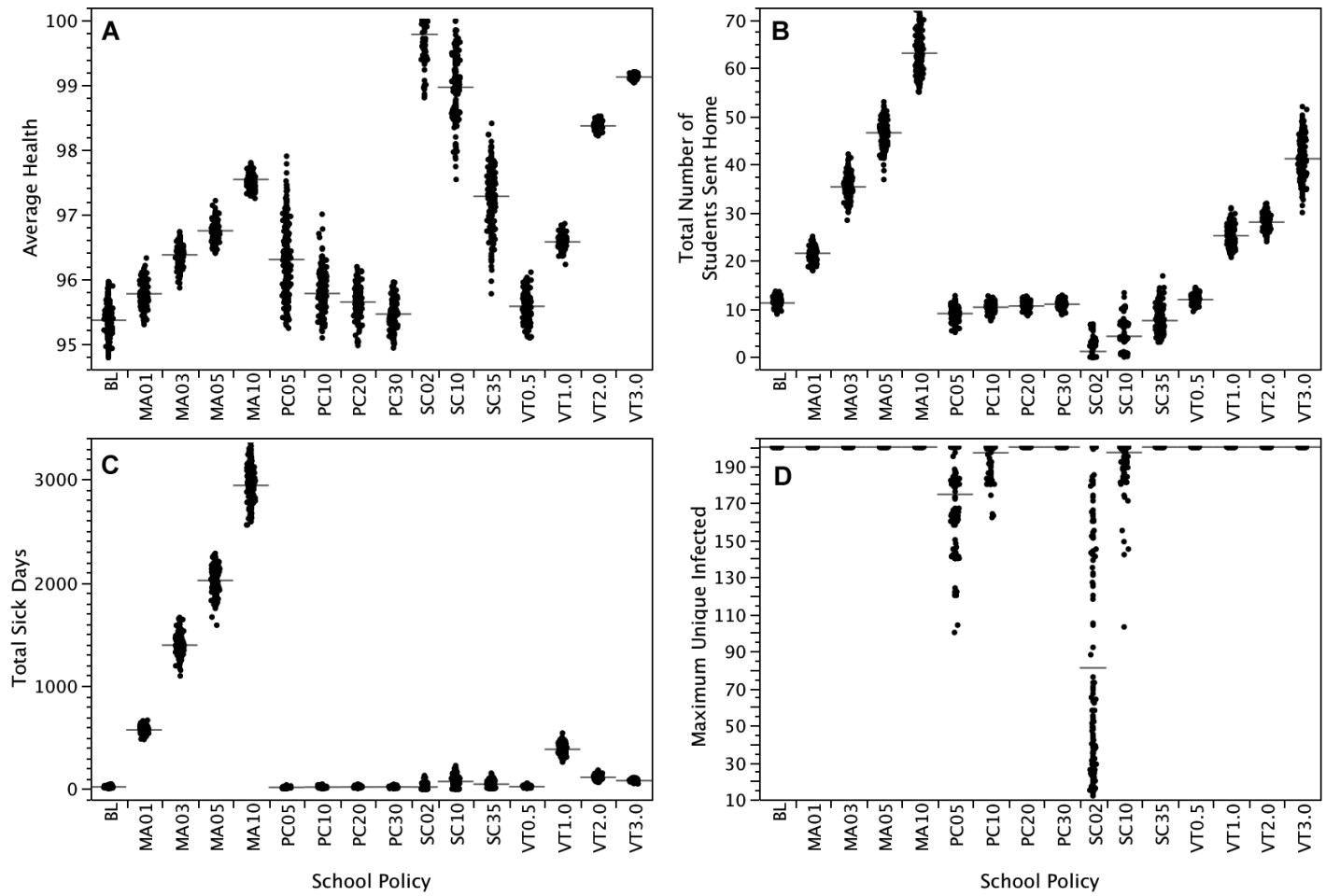

Fig. 2. Effect of school policy on model outcomes. Examining the relative efficacy of a number of pandemic preparedness plans on the health and attendance of school students. Outcomes of interest were the average health score for (A) the students out of 100, (B) the mean number of students who had been sent home at any given time point, (C) the total number of sick days experienced by the students, and (D) the maximum number of unique infected students out of 200. (Data points jittered to clarify distribution of data; single solid line represents the mean value.)

policy's ability to obstruct the spread of an epidemic, protecting the students and, indirectly, the broader community. Of the modeled scenarios, only two managed to significantly halt the epidemic's spread. Closing the playground/common area when $5 \%$ of the students were symptomatic achieved an average number of unique infected students of 174.49 , while closing the school when $2 \%$ of students were symptomatic resulted in an average of 80.91 . Playground closing and school closure at $10 \%$ and $5 \%$, respectively also managed to produce sub-200 scores, but these were not statistically significant (one-way ANOVA: $F=761.19, p<0.005$, post-hoc testing with Tukey's HSD, $\alpha=0.05$ ).

The burden of school absence reflected in total sick days also found significant differences between the modeled policies. A policy mandating a 10-day absence for symptomatic students produced an average of 2939.35 sick days for the student population, with the other mandatory absence policies following it. Playground closing, school closure, the variable threshold policy with a coefficient value of 0.5 and the baseline policy all produced an average number of sick days for their students between 16.76 and 23.34, although these were not found to be significantly different using pair-wise comparison testing (one-way ANOVA: $F=67834.58, p<0.005$, post-hoc testing with Tukey's HSD, $\alpha=0.05$ ). Again, it should be noted that the number of sick days only represents children being kept home because they are symptomatic, and does not reflect non-school time being spent at home or in other daytime care facilities due to school closure. This was confirmed by a high total number of hours missed compared to non-closure based models, which reflects missed school due to both to student sent home and school closure (data not shown). 


\section{Discussion}

Our results clearly show that open-school policies can be effective in disease control, though the extent to which each will provide sufficient protection will rely on disease-specific variables not exhaustively considered here. The potentially severe social and health-related ramifications of school closure as a preventative measure lead us instantly to the conclusion that policies mitigating those effects, while still providing reasonable measures to interrupt in-school disease transmission, may provide the best societal outcomes. The modeling studies which have indicted schools as potential amplifiers of epidemics have all done so as the result of current school structures and policies. If we were able to lower in-school transmission to levels even somewhat similar to those for adults at work, or families at home, it may be that we would rid ourselves of the amplification potential, making schools "just another concern", rather than one of the lead forces driving the propagation of infection.

The healthier performance of the classroom structure, as opposed to the single area configuration, not surprisingly indicates that schoolwide mixing rate itself can drive the course of in-school spread. However, it is important to place these configurations in their correct context: the classroom structure is of much more common use in earlier school grade levels, while the single area model was meant to represent high school levels. The differences in behavior, hygiene and physiological immunocompetence between these two age groups may easily have more of an effect on disease dynamics than the social organization imposed by school architecture. Of course, when reinterpreting the single area studies to represent 'sick day care', rather than high school, the implications are far more serious (see further discussion below).

Among the policies considered, the continuations and extensions of the existing mandatory absence policies, in the face of a rapidly spreading infectious disease, failed to curtail the epidemic. They showed markedly low average health of the student body and a large number of missed school days. At the other end of the spectrum, outright closure of the schools, espe- cially when very small numbers of students were actually sick performed extremely well, as was expected. The question of the practicality of these policies is, however, problematic. Closing a school when $2 \%$ of the student population is sick is both an unrealistically optimistic target for sensitivity in the detection of illness, and creates massive amounts of absenteeism rooted in school closure, essentially forcing parents to find alternative daytime arraignments for their children for the duration of the pandemic. Of course, this already assumes that reasons for absenteeism are known. Realistically, students rarely inform schools of the reasons for their absence, and daily absentee rates, especially in urban settings (of great concern in pandemic scenarios), can easily be nearly $8 \%$ in the absence of pandemic infection. Unfortunately, merely noting a $2 \%$ increase in absenteeism does not necessarily indicate anything related to disease (cf. Besculides et al. 2003).

Additionally, as these policies must be in place ahead of time, and the emergence of a pandemic will likely have a high degree of epidemiological uncertainty around it. Even if we were able to define "significant increase" to estimate when an "additional $2 \%$ absence" could be attributed to disease, it is still likely that this sensitive school closure model will send large numbers of children home for "false alarms", even when pandemic disease is expected or already present in the broader community. Families and communities incurring these costs, not to mention the compromised education of children themselves, makes this a difficult path to embrace without further study.

The scenarios modeling alternatives to the aforementioned, more traditional policies provide some potential insight into viable alternatives. The models built on a variable threshold value for sending students home suggest a middle ground between mandatory absence and school closure policies, enjoying high levels of student health with a low number of total sick days. Similarly, models focusing on closing the school's common areas were remarkably capable of slowing or halting the spread of an epidemic within the school. While student health was, relatively speaking, on the low end of the modeled scenarios - as children were not being 
sent home to recover as frequently - there were very low numbers of sick days and students sent home, and the most sensitive playground closing model $(5 \%)$ was the only scenario besides the unrealistic $2 \%$ school closure model that proved capable of protecting some of the students from ever being infected. While $5 \%$ is still quite sensitive, it is considerably less so than the comparable school closure model, and importantly the consequences for a false alarm are in the realm of mild childhood disappointment, or schedule disruptions for older students, rather than an entire school being sent home.

Most importantly perhaps, central to any evaluation of efficacy of any school closure policy towards achieving the goal of infection control are the findings from the school structure models. It is unreasonable to expect that, if a child is sent home or a school is closed entirely, that all, or even the majority, of the affected families will be able to keep a parent home to care for the child full-time. For many, circumstances would force finding alternate care for their children in the hands of a third-party, and many foreseeable solutions, such as one parent supervising a group of children or a community center, entail returning children to a pool of their presumably infected peers. These settings are, at best, less structured versions of a day school environment. All model results for such unstructured settings have worse outcomes than a structured school, with the lowest average health of any model. These results are in keeping with empirically established infection risks from day care centers under normal, healthy conditions (e.g. Hernández et al. 1999) and we can only presume that they would not improve during epidemic outbreaks.

Our model is not by any means a comprehensive or complete examination of the possible school policies that should be considered in the event of a pandemic. What is important to glean from the results, however, is that alternative strategies provide unexpected, and often potentially beneficial outcomes. With the pace new pandemic preparedness strategies are being implemented, it is crucial that some thought and consideration be given to the economic and social consequences stemming from the secondary effects of school closure policies. It is possible, with careful and deliberate planning before the arrival of a major wave of infectious disease, to enact a strategy, based upon rigorous empirical testing, that will both help soften the blow of mass infection and assist in maintaining a functioning societal infrastructure.

\section{References}

Besculides, M., Heffernan, R., Mostashari, F. \& Weiss, D. 2003: Evaluation of school absenteeism data for early outbreak detection - New York City, 2001-2002. Syndromic surveillance: reports from a national conference, 2003. - Morbidity and Mortality Weekly Report 53(Suppl): 230.

Bhat, N., Wright, J. G., Broder, K. R., Murray, E. L., Greenberg, M. E., Glover, M. J., Likos, A. M., Posey, D. L., Klimov, A., Lindstrom, S. E., Balish, A., Medina, M. J., Wallis, T. R., Guarner, J., Paddock, C. D., Shieh, W. J., Zaki, S. R., Sejvar, J. J., Shay, D. K., Harper, S. A., Cox, N. J., Fukuda, K. \& Uyeki, T. M. 2005: Influenzaassociated deaths among children in the United States, 2003-2004. - New England Journal of Medicine 353: 2559-2567.

Black, R. E., Morris, S. S. \& Bryce, J. 2003: Where and why are 10 million children dying every year? - The Lancet 361: 2226-2234.

Bocchini, J. A. Jr., Bernstein, H. H., Bradley, J. S., Brady, M. T., Byington, C. L., Dennehy, P. H., Frenck, R. W. Jr., Glode, M. P., Keyserling, H. L., Kimberlin, D. W., Long, S. S. \& Rubin, L. G. 2008: Prevention of influenza: recommendation for influenza immunization of children, 2007-2008. - Pediatrics 121: e1016-e1031.

Broward County Public Schools Pandemic Action Plan 2006: Document available at http://www.browardschools.com/ info/pdf/draft_checklist.pdf.

Community Strategy for Pandemic Influenza Mitigation - PandemicFlu.gov 2007: Document available at http:// www.pandemicflu.gov/plan/community/commitigation. html.

Conly, J. M. \& Johnston, B. L. 2003: Norwalk virus - off and running. - Canadian Journal of Infectious Diseases 14: 11-13.

Dyer, D. L., Shinder, A. \& Shinder, F. 2000: Alcohol-free instant hand sanitizer reduces elementary school illness absenteeism. - Family Medicine 32: 633-638.

Hammond, B., Ali, Y., Fendler, E., Dolan, M. \& Donovan, S. 2000: Effect of hand sanitizer use on elementary school absenteeism. - American Journal of Infection Control 28: 340-346.

Hernández, S. F., Morales, H. R., Cuevas, R. P. \& Gallardo, H. G. 1999: The day care center as a risk factor for acute respiratory infections. - Archives of Medical Research 30: 216-23.

Pandemic Influenza Preparedness and Response Guidance for Healthcare Workers and Healthcare Employers - OSHA 3328-05 2007: Document available at http://www.osha. gov/Publications/OSHA_pandemic_health.pdf. 
Pandemic Preparedness - New York Department of Education 2006: Document available at http://www.emsc. nysed.gov/fmis/pandemic.htm.

Ridzon, R., Kent, J. H., Valway, S., Weismuller, P., Maxwell, R., Elcock, M., Meador, J., Royce, S., Shefer, A., Smith, P., Woodley, C. \& Onorato, I. 1997: Outbreak of drug-resistant tuberculosis with second-generation transmission in a high school in California. - The Journal of Pediatrics 131: 863-868. doi:10.1016/S00223476(97)70034-9.
Secretary Spellings Address to the North Carolina Pandemic Planning Summit 2006: Document available at http:// www.ed.gov/news/pressreleases/2006/03/03212006a. html.

Suarez, D. L. 2005: Overview of avian influenza DIVA test strategies. - Biologicals 33: 221-226.

Villar, L. M., do Carmo, M., da Costa, E., de Paula, V. S. \& Gaspar, A. M. C. 2002: Hepatitis A outbreak in a public school in Rio de Janeiro, Brazil. - Memorias do Instituto Oswaldo Cruz 97: 301-305. 